\title{
Atypical functioning of female genitalia explains monandry in a butterfly
}

\author{
David Xochipiltecatl ${ }^{1}$, Joaquín Baixeras ${ }^{2}$, Carlos R Cordero ${ }^{\text {Corresp. } 3}$ \\ ${ }^{1}$ Posgrado en Ciencias Biológicas, Instituto de Ecología, Universidad Nacional Autónoma de México, Mexico City, Mexico City, México \\ 2 Institut Cavanilles de Biodiversitat i Biologia Evolutiva, Universitat de València, Paterna, Valencia, Spain \\ 3 Departamento de Ecología Evolutiva, Universidad Nacional Autónoma de México, Mexico City, Mexico City, México \\ Corresponding Author: Carlos R Cordero \\ Email address: cordero@ecologia.unam.mx
}

Monandrous species are rare in nature, especially in animals where males transfer nutrients to females in the ejaculate. The proximate mechanisms responsible for monandry are poorly studied. In butterflies and moths, the male transfers a nutritious spermatophore into the corpus bursae $(C B)$ of the female. The $C B$ is a multifunctional organ that digests the spermatophore and has partial control of the post-mating sexual receptivity of the female. The spermatophore distends the $C B$ and the post-mating sexual receptivity of the female is inversely proportional to the degree of distension. The CB of many butterfly species has a muscular sheath whose contractions mechanically contribute to digest the spermatophore. As the contents of the CB are absorbed, the degree of distension decreases and the female recovers receptivity. We studied the monandrous butterfly Leptophobia aripa (Boisduval, 1836) (Pieridae) and found that females do not digest the spermatophores. We investigated the structure of the CB and found that a muscular sheath is absent, indicating that in this butterfly females lack the necessary "apparatus" for the mechanical digestion of the spermatophore. We propose that female monandry in this species is result of its incapability to mechanically digest the spermatophore, which results in a constant degree of CB distension after mating and, thus, in the maintenance of the sexually unreceptive state of females. Hypotheses on the evolution of this mechanism are discussed. 


\section{Atypical functioning of female genitalia explains monandry in a butterfly}

2

3 David Xochipiltecatl ${ }^{1}$, Joaquín Baixeras ${ }^{2}$, Carlos Cordero ${ }^{3}$

4

$5 \quad{ }^{1}$ Posgrado en Ciencias Biológicas, Instituto de Ecología, Universidad Nacional Autónoma de

6 México, 04510 Ciudad de México, México

$7{ }^{2}$ Institut Cavanilles de Biodiversitat i Biologia Evolutiva, Universitat de Valencia, Paterna, ES-

846980 Valencia, Spain

9 32Departamento de Ecología Evolutiva, Instituto de Ecología, Circuito exterior s/n, Ciudad

10 Universitaria, Universidad Nacional Autónoma de México, 04510 Ciudad de México, México

12 Corresponding author:

13 Carlos Cordero

14 E-mail address: cordero@ecologia.unam.mx 


\section{ABSTRACT}

16 Monandrous species are rare in nature, especially in animals where males transfer nutrients to

17 females in the ejaculate. The proximate mechanisms responsible for monandry are poorly

18 studied. In butterflies and moths, the male transfers a nutritious spermatophore into the corpus

19 bursae $(\mathrm{CB})$ of the female. The $\mathrm{CB}$ is a multifunctional organ that digests the spermatophore and

20 has partial control of the post-mating sexual receptivity of the female. The spermatophore

21 distends the $\mathrm{CB}$ and the post-mating sexual receptivity of the female is inversely proportional to

22 the degree of distension. The CB of many butterfly species has a muscular sheath whose

23 contractions mechanically contribute to digest the spermatophore. As the contents of the CB are

24 absorbed, the degree of distension decreases and the female recovers receptivity. We studied the

25 monandrous butterfly Leptophobia aripa (Boisduval, 1836) (Pieridae) and found that females do

26 not digest the spermatophores. We investigated the structure of the $\mathrm{CB}$ and found that a muscular

27 sheath is absent, indicating that in this butterfly females lack the necessary "apparatus" for the

28 mechanical digestion of the spermatophore. We propose that female monandry in this species is

29 result of its incapability to mechanically digest the spermatophore, which results in a constant

30 degree of CB distension after mating and, thus, in the maintenance of the sexually unreceptive

31 state of females. Hypotheses on the evolution of this mechanism are discussed. 


\section{INTRODUCTION}

Monandrous species, in which most females copulate just with one male, are rare in most animal groups (Pizzari \& Wedell, 2013; Taylor, Price \& Wedell, 2014). There are two general hypotheses to explain the existence of monandry. First, monandry could be selected for when females maximize their fitness with just one mating, which could happen if, for example, polyandry imposes high costs on females (Arnqvist \& Andrés, 2006; Jiggins, 2017). Second, if polyandry increases female fitness, sperm competition could favour male adaptations that impose monandry and, in consequence, fitness costs on females (Hosken et al., 2009). Different female adaptations are expected to evolve in each case. For example, if monandry is adaptive for females, they could evolve structures that facilitate the deposition and storage of male-derived anti-aphrodisiacs, as in Heliconius butterflies (Jiggins, 2017). On the other hand, if males impose monandry selection could favour the evolution of counter-adaptations, female traits that prevent or reduce male manipulation, as the anti-antiaphrodisiacs of the plant bug Lygus hesperus (Brent, Byers \& Levi-Zada, 2017). These examples show that understanding the proximate mechanisms preventing female remating sheds light on the ultimate causes of monandry.

During copulation, male lepidopterans transfer ejaculates, mostly contained within a spermatophore, into a bag-shaped organ of the female reproductive tract known as corpus bursae (CB hereafter) (Drummond 1984; Watanabe \& Sato, 1993; Watanabe, 2016; Meslin et al., 2017). In most butterflies and moths studied to date, the ejaculates are rich in nutrients (Boggs \& Gilbert, 1979; Marshall, 1985; Pivnick \& McNeil, 1987; Boggs, 1990; Lai-Fook, 1991; Watanabe \& Sato, 1993; Bissoondath \& Wiklund, 1995, 1996a, 1996b; Karlsson, 1998; Molleman et al., 2005; Watanabe, 2016; Meslin et al., 2017; Cannon, 2020) and other chemical compounds (Dussourd et al., 1988, 1989; Eisner \& Meinwald, 1995; Smedley \& Eisner, 1996; 
56 Cardoso, Roper \& Gilbert, 2009; Watanabe, 2016) that enhance female fitness (Vahed, 1998;

57 Arnqvist \& Nilsson, 2000; Oberhauser, 1989; Eisner \& Meinwald, 1995; González et al., 1999;

58 Torres-Vila, Rodríguez-Molina \& Jennions, 2004; Torres-Vila \& Jennions, 2005; Watanabe,

59 2016; Meslin et al., 2017; Cannon, 2020). The fact that most of these components are

60

61

62 unavailable in the adult diet adds to their importance for female fitness and explains, in some extent, the ubiquity of polyandry in this group (Drummond, 1984; Eberhard, 1985; Simmons, 2001; Sánchez, Hernández-Baños \& Cordero, 2011; Cannon, 2020). However, intriguingly, in Lepidoptera there are some monandrous species (Drummond, 1984; Eberhard, 1985; Walters et al., 2012; Caballero-Mendieta \& Cordero, 2013; Konagaya, Idogawa \& Watanabe, 2020).

After mating, female butterflies of polyandrous species become sexually unreceptive for a period of time (Sugawara, 1979; Drummond, 1984; Oberhauser, 1989, 1992; Kaitala \& Wiklund, 1995). During this refractory period, the sperm is transferred from the spermatophore to the spermatheca, its final storage place within the female. The resource-rich spermatophore is gradually digested within the CB (Drummond, 1984; Oberhauser, 1992; Galicia, Sánchez \& Cordero, 2008; Walters et al., 2012; Meslin et al., 2015; Plakke et al., 2015; Watanabe, 2016). At the proximate level, female sexual receptivity and mating frequency are controlled by multiple factors (Sugawara, 1979; Drummond, 1984; Wedell, 2005). One important factor is the mechanical stimulation resulting from distension of the CB by the spermatophore (Labine, 1964; Sugawara, 1979; Oberhauser, 1992). Sugawara (1979) clearly demonstrated that reception of a spermatophore in the butterfly Pieris rapae (Pieridae) induces females to display mate rejection behaviour when courted and that stretch receptors on the surface of the CB are involved in this behavioural change. Sugawara (1979) showed that the frequency of afferent nervous impulses from the stretch receptors increase tenfold after reception of a spermatophore, however, females 
remain sexually receptive if the $\mathrm{CB}$ is filled with less than half the volume of an average spermatophore (recently and multiply mated males produce smaller spermatophores). In polyandrous species, female receptivity is gradually recovered as the amount of spermatophore remaining in the corpus bursa decreases (Oberhauser, 1989,1992) due to its digestion and absorption (Boggs \& Gilbert, 1979; Lai-Fook, 1986; Galicia, Sánchez \& Cordero, 2008; Meslin et al., 2015; Plakke et al., 2015).

Besides its effect on female receptivity, the presence of a spermatophore in the CB triggers the periodical contraction of the muscles surrounding the CB (Sugawara, 1979), resulting in tearing of the spermatophore envelope with the sclerotized structures located in the inner wall of the CB (called signa) and the mechanical digestion of the spermatophore contents (Sugawara, 1979; Rogers \& Wells, 1984; Tschudi-Rein \& Benz, 1990; Galicia, Sánchez \& Cordero, 2008). The frequency of contractions of the CB muscles is directly correlated with the volume of the spermatophore (Sugawara, 1979). In species lacking signa, such as Calpodes ethlius (Hesperiidae), mechanical tearing and digestion of the spermatophore is also achieved via the "relatively violent" contractions of the muscles surrounding the CB (Lai-Fook, 1986: p. 556). The ubiquity of the mechanical digestion function of the $\mathrm{CB}$ is supported by transcriptomic studies showing highly expressed genes whose products are biased towards muscle organization and activity in the $\mathrm{CB}$ of P. rapae (Meslin et al., 2015) and the moth Ostrinia nubilalis (Crambidae) (Al-Wathiqui, Lewis \& Dopman, 2014; Al-Wathiqui, Dopman \& Lewis, 2016). More generally, the presence and layout of well-developed muscles surrounding the $\mathrm{CB}$, and their common association with the signa, is consistent with a mechanical digestion function of the CB in Lepidoptera (Sugawara, 1979; Drummond, 1984; Rogers \& Wells, 1984; Kristensen, 2003; Lincango, Fernández \& Baixeras, 2013). Spermatophore digestion is not only mechanical, 
102 but also biochemical, although this last process is less well understood (Al-Wathiqui, Dopman \&

103 Lewis, 2016). Transcriptomic and proteomic studies of the CB support the idea that the

104 spermatophore is also enzymatically digested (Al-Wathiqui, Lewis \& Dopman, 2014; Meslin et

105 al., 2015; Al-Wathiqui, Dopman \& Lewis, 2016) and pioneering studies of the CB of P. rapae

106 show its proteolytic activity (Plakke et al., 2015) and have characterized some of the proteases

107 involved (Plakke et al., 2019).

A third function of the $\mathrm{CB}$ is the absorption and transport of substances contained in the spermatophore. In his general review of lepidopteran genitalia, Kristensen (2003: p. 438) mentions the following: "The bursa is obviously capable of absorbing breakdown compounds from the spermatophore". This function was demonstrated in C. ethlius (Lai-Fook, 1991) and is consistent with radiotracer studies in three nymphalid species (Boggs \& Gilbert, 1979), transcriptomic studies in $P$. rapae identifying highly expressed genes associated to the transport function (Meslin et al., 2015), the presence of pores and the structure of epithelial cells in the monarch butterfly (Rogers \& Wells, 1984), and observations of pores on the inner surface of the $\mathrm{CB}$ of several species of moths in the family Tortricidae (Lincango, Fernández \& Baixeras, 2013; although these authors suggest pores could be involved in secretion of substances to the interior of the $\mathrm{CB}$ ). spermatophore turns-off sexual receptivity and triggers contractions of the muscles surrounding the $\mathrm{CB}$ that result in the piercing or tearing of the spermatophore envelope and the mechanical digestion of its contents (Sugawara, 1979; Lai-Fook, 1991). Female receptivity is recovered as the amount of spermatophore remaining in the CB decreases (Sugawara, 1979; Oberhauser,

124 1989,1992) due to digestion and absorption in the CB (Boggs \& Gilbert, 1979; Lai-Fook, 1991; 
125 Galicia, Sánchez \& Cordero, 2008; Meslin et al., 2015; Plakke et al., 2015; Watanabe, 2016).

126 Thus, the CB plays a fundamental role in the control of sexual receptivity (although it is not the

127 only factor; see Wedell, 2005) and mating frequency in female Lepidoptera and, therefore, it is

128 an obvious place to look for genital adaptations to monandry in Lepidoptera (Cordero \&

129 Baixeras, 2015).

Here, we report observations regarding the possible mechanism responsible for female

131

132

133

134

135

136

137

138

139

140

141

142

143

144

145

146 counts in mated females (Caballero-Mendieta \& Cordero, 2013). We studied the fate of the

spermatophore within the $\mathrm{CB}$ with the aim of measuring its rate of digestion and, surprisingly,

found that the spermatophore does not show any sign of being digested. To shed light on why the spermatophore is not digested, we studied the musculature of the $\mathrm{CB}$, as well as the fine structure of its inner surface. We found that L. aripa lacks the necessary "apparatus" for the mechanical digestion of the spermatophore.

\section{Materials and Methods}

\section{Butterflies studied and laboratory rearing}

L. aripa is the most abundant butterfly in Mexico City, flying all year (Díaz-Batres \& LlorenteBousquets, 2011). Their caterpillars feed on a variety of plant species and are considered a pest of cabbage, broccoli and cauliflower crops in México and Central America (CATIE/MIP, 1990). The butterflies used in our experiments and in most observations were the offspring of females collected in the Ciudad Universitaria campus of the Universidad Nacional Autónoma de México

Peer] reviewing PDF | (2021:07:63471:1:0:NEW 28 Sep 2021) 
147 (CU-UNAM), located in southern Mexico City. Individual females were fed ad libitum every

148 morning a 10\% sugar solution and allowed to lay eggs in plastic containers with fresh leaves of

149 Tropaeolum majus (Tropaeolaceae), the main food plant in our study location. To stimulate

150 oviposition, the containers, covered with mesh cloth, were located under (about $20 \mathrm{~cm}$ ) an

151 incandescent white light bulb for 90 minutes, although females frequently lay eggs even in the

152 absence of these bulbs. The larvae were reared individually in small plastic containers $(10 \mathrm{~cm}$

153 diameter, $4 \mathrm{~cm}$ height) with $T$. majus fresh leaves. Upon emergence, adults were individually

154 marked on the wings with a permanent marker (Sharpie $\left.{ }^{\mathrm{TM}}\right)$ and kept individually in the same

155 plastic containers in which they were reared.

156

157

158

159

160

161

162

163

164

165

166

167

168

169

\section{Experiment on the fate of the spermatophore within the corpus bursae}

This experiment was originally designed to determine the pattern of digestion of the spermatophore within the CB. Virgin females were mated with virgin males and euthanized by freezing at different times after the end of copulation $(0,8,16,24,48,72$ and 96 hours). Matings were obtained by placing males and females in cylindrical cages made of mesh cloth and metal wire ( $\sim 60 \mathrm{~cm}$ height and $\sim 25 \mathrm{~cm}$ diameter) in the gardens of the Instituto de Ecología, located in CU-UNAM, between 10AM and 15PM (Mexico City time). With exception of the females frozen immediately after finishing copulating $(0 \mathrm{~h})$, all experimental females were allowed to lay eggs daily as explained above. All females laid eggs and in most cases these were numerous, although they were not counted.

The frozen females were thawed at ambient temperature and their abdomens separated from the body, opened and cleaned with forceps. Then, the CB and the spermatophores were carefully dissected out, thoroughly examined and photographed under a stereomicroscope (Olympus ${ }^{\mathrm{TM}} \mathrm{BX} 51$ ). A total of 48 females were studied: $\mathrm{N}_{0 \mathrm{~h}}=6$ females, $N_{8 \mathrm{~h}}=7, N_{16 \mathrm{~h}}=7, N_{24 \mathrm{~h}}$ 
$170=8, N_{48 \mathrm{~h}}=8, N_{72 \mathrm{~h}}=6$, and $N_{96 \mathrm{~h}}=6$. These times were chosen because females under laboratory

171 conditions lay most of their eggs within four or five days after mating, and few live more than a

172 week, despite being fed daily (D. Xochipiltecatl, personal observations). In each spermatophore

173 photograph, we measured the area covered by the spermatophore with the ImageJ open access

174 software (National Institutes of Health USA, http://rsb.info.nih.gov.ij/). We used this area as a

175 proxy of spermatophore size. We compared the effect of time after mating on the area of the

176 spermatophore with a Kruskal-Wallis ANOVA.

\section{Preparation of samples for microscopic observation}

178 Observations and photographs of the $\mathrm{CB}$, the ductus bursae (the duct connecting the $\mathrm{CB}$ with the copulatory pore known as the ostium; Fig. 1) and the spermatophore, of dry and fixed specimens (see below), were made with stereomicroscopes (Olympus ${ }^{\mathrm{TM}} \mathrm{BX} 51$ and Leica ${ }^{\mathrm{TM}} \mathrm{MZ8}$ ) and a scanning electron microscope (SEM; Hitachi $\left.{ }^{\mathrm{TM}} \mathrm{S} 4800\right)$.

For observation of the muscles associated with the CB and ductus bursae (DB hereafter) we used two methods. First, three laboratory-reared virgin females were placed in a freezer at $20{ }^{\circ} \mathrm{C}$ for about 3 minutes and then gently injected with Karnovsky's fixative (paraformaldehyde $2 \%$ / glutaraldehyde $2.5 \%$ ) in the body cavity through the thorax and the abdomen. Then the abdomen was separated from the rest of the body and submerged in the same fixative until dissection. For SEM observation, the abdomens were transferred to centrifuge tubes with phosphate buffer $0.1 \mathrm{M}$ and rinsed during several minutes in a shaker (MRS-Mini Rocket Shaker, Biosan $\left.^{\mathrm{TM}}\right)$. Then, the abdomens were carefully removed and cleaned with forceps, and the CB and DB were dissected out, stained with $2 \%$ osmium tetroxide for 20 minutes followed by Pella Inc., product number 4619) and dehydrated in increasing grade ethanol. The CB and DB 
193 were then dried to critical point in an Autosamdry $814^{\mathrm{TM}}$ (Tousimis), positioned on SEM stubs

194 using carbon tape and silver conducting paint and sputtered with Au-Pd. For comparison

195 purposes, similar procedures were applied to two females of the common African leafworm,

196 Spodoptera littoralis (Boisduval, 1833). This noctuid species allows easy recognition of the

197 musculature associated to the CB.

We also observed the muscles associated to the CB and DB in three field collected mated 199 females (captured while laying eggs) that were brought to the laboratory and allowed to continue laying eggs (one female two days and two females three days), before being euthanized by freezing at $-70{ }^{\circ} \mathrm{C}$ and then their abdomens were separated from the body and preserved in $100 \%$ ethylic alcohol. The abdomens were carefully opened and the CB and DB dissected out and carefully cleaned, with micro-scissors, fine forceps and fine brushes, in glass embryo dishes under the stereomicroscope. The spermatophores contained in these females were also used to confirm that they are not digested in the CB (see Results).

For observation of the inner surface of the CB in the SEM, we used three laboratoryreared virgin females, two of them preserved dry and one fixed (with paraformaldehyde $2 \%$ / glutaraldehyde $2.5 \%$ ) as explained above. The abdomen of the fixed specimen was rinsed in phosphate buffer $0.1 \mathrm{M}$, as explained above. The abdomens were separated from the rest of the body and digested in $10 \% \mathrm{KOH}$ at $90{ }^{\circ} \mathrm{C}$ for about 90 minutes. Then, the abdomens were stained

211 for about 30 seconds in chlorazol black $\left(0.1 \%\right.$ in ethanol $\left.70^{\circ}\right)$ and the $\mathrm{CB}$ was removed, carefully

212 cleaned and cut longitudinally. Subsequent digestions with $\mathrm{KOH}$ were performed when needed.

213 Fragments were processed in a similar way to the treatment of complete CB and DB.

\section{Results}




\section{The spermatophore is not digested in the corpus bursae}

217 Forty-eight virgin females were mated with virgin males and frozen at different times after the

218 end of copulation. These females had their spermatophores carefully dissected and thoroughly

219 examined under the dissection microscope. Despite the fact that most females laid eggs before

220 being dissected (the exception being the females frozen immediately after mating), the

221 spermatophores contained in the CB of all females remained physically intact independently of

222 the time elapsed after the end of copulation (Fig. 2). There was no sign of rupture on the external

223 surface of the spermatophore or of spermatophore deflation (Fig. 2). In agreement with these

224 observations, the area covered by the spermatophore, our proxy of spermatophore size, did not

225 vary with time lapsed after copulation (Kruskal-Wallis test: $H=4.26, P=0.64, d f=6$; Fig. 3 ).

226 The bulbous spermatophore occupies most of the CB (Fig. 1B), is bilobed (Fig. 4A) and

227 has a tubular prolongation, called the collum, which extends along the DB (Fig. 1B, 2 and 4A),

228 blocking it almost completely (Fig. 1B). Only the area of the spermatophore that is in contact

229 with the signum looked somewhat deformed but not broken (Fig. 4A).

230

These observations were corroborated with detailed SEM observations of the

231

232

233

234

235

236

237 spermatophores obtained from the three females collected in the field while laying eggs. As

observed in the previous experiment, the external envelopes of these spermatophores were also intact although somewhat compressed near the signum (Fig. 4A). No deflation, perforations or tearing were observed in any of them (Fig. 4A). Thus, our observations indicate that the spermatophore is not digested at least up to four days after mating, which is enough time for females to lay most of their eggs under laboratory conditions (D. Xochipiltécatl, personal observations). 
238 The corpus bursae lacks the necessary "apparatus" for the mechanical digestion of the

\section{9 spermatophore}

240 The observation of the CB of Lepidoptera under the optical microscope allows detection of

241 sclerotizations (signa) and folds. The observation under SEM of the external surface of the CB of

242 many species (such as $S$. littoralis) reveals the presence of a muscular lining over the integument.

243 Muscles appear as bundles of parallel fibers (Figs. 4C and 4F) easily distinguishable from folds

244 and other structural components. The integument of the CB of L. aripa through the optical

245 microscope (Fig. 1A) appears rather uniform, smoothly rough, and somewhat transversally

246 corrugated. Except for the presence of the signum near the junction area of the DB and CB

247 (known as the cervix bursae), no sclerotization is detectable. Observations through SEM of the

248 CB of virgin and mated females of L. aripa (Figs. 4B and 4E) fixed either with

249 formaldehyde/glutaraldehyde $(\mathrm{N}=3)$ or with absolute ethylic alcohol $(\mathrm{N}=3)$ did not show

250 muscles enveloping the CB (Fig. 4B), thus indicating that mechanical digestion of the

251 spermatophore is not feasible in this species. The integument is directly exposed on the CB and

252 follows the corrugation observable through the optical microscope. The DB, on the contrary, is

253 covered with muscle fibers extending from a ventromedial line, which gives its superficially

254 striated appearance (Figs. 4B and 4E). Some of these fibers are inserted in the cervix, at the level

255 of the signum. They could help this structure to exert pressure and deform the spermatophore

256 without breaking it (Fig. 4A).

257

Detailed observations in the SEM of the inner surface of the CB showed a complete

258 absence of pores (Fig. 4D).

259

260

Discussion

Peer] reviewing PDF | (2021:07:63471:1:0:NEW 28 Sep 2021) 
261 In this paper, we show that in the butterfly L. aripa the spermatophore remains intact within the

262 CB at least up to four days after mating (Fig. 2), the period during which females lay most of

263 their eggs in captivity (D. Xochipiltecatl, personal observations). In agreement with these

264 observations, the area covered by the spermatophore (a proxy of its size) did not decrease with

265 the time lapsed after the end of copulation (Fig. 3). These observations indicate that in this

266 butterfly females do not digest the spermatophores, in contrast with most lepidopterans studied

267 (Drummond, 1984; Oberhauser, 1992; Galicia, Sánchez \& Cordero, 2008; Walters et al., 2012;

268 Meslin et al., 2015; Plakke et al., 2015; Watanabe, 2016). We also show that there are no

269 muscles enveloping the CB. Since in other lepidopterans the spermatophore is mechanically

270 digested due to the contractions of the muscular sheath of the CB (Sugawara, 1979; Rogers \&

271 Wells, 1984; Lai-Fook, 1986; Al-Wathiqui, Lewis \& Dopman, 2014; Meslin et al., 2015), we

272 propose that the absence of a muscular sheath prevents the CB from digesting mechanically the

273 spermatophore. In other words, females of this species lack the "apparatus" required for the

274 mechanical digestion of spermatophores. Furthermore, judging from the intact condition of the

275 spermatophores several days after mating in females that laid eggs during several days,

276 enzymatic digestion also seems to be absent. The observed absence of pores on the inner surface

277 of the $\mathrm{CB}$ is also consistent with this idea because pores could be involved both in the absorption

278 of products from digestion of spermatophores (Lai-Fook, 1986), and in the secretion of

279 molecules used for the chemical digestion of spermatophores within the CB, as suggested for

280 Tortricidae (Lincango, Fernández \& Baixeras, 2013).

281 In the introduction, we reviewed evidence indicating that in many Lepidoptera female

282 sexual receptivity is at least partially controlled by the mechanical stimulation (distension) of the

$283 \mathrm{CB}$ by the spermatophore. The degree of distension of the $\mathrm{CB}$ is inversely related to the sexual 
284 receptivity of females, and the receptivity is recovered as the ejaculate is digested and the CB

285 deflates (Labine, 1964; Sugawara, 1979; Oberhauser, 1992). L. aripa females tend to be

286 monandrous (Caballero-Mendieta \& Cordero, 2013) and we propose that female monandry in

287 this species is a result of its incapability to mechanically digest the spermatophore, which results

288 in a constant degree of CB distension after mating and, thus, in the maintenance of the sexually

289 unreceptive state of females. Thus, we propose that the absence of muscles enveloping the CB

290 explains monandry in L. aripa. A possible explanation for the rare cases of twice-mated females

291 in this species (Caballero-Mendieta \& Cordero, 2013) is that their first mate was recently mated

292 and/or small, since both male conditions are known to result in the transfer of smaller

293 spermatophores (Caballero-Mendieta \& Cordero, 2013). This hypothesis can be tested by

294 comparing remating rates of females mated to virgin/average sized males with those of females

295 mated with recently mated/small males.

As mentioned in the Introduction (references therein), many male lepidopterans produce spermatophores rich in nutrients and other chemical compounds that enhance female fitness.

Since these "nuptial gifts" are costly to produce (Shapiro, 1982; Cordero, 2000; Ferkau \&

Fischer, 2006; Caballero-Mendieta \& Cordero, 2013), we predict that in L. aripa selection digest spermatophores. 
307 expectancy of a female in the wild" (Drummond, 1984: p. 303). We predict that these species are

308 monandrous and possibly have a CB devoid of a muscular sheath. Also, it will be interesting to

309 study if the CB of known monandrous butterflies and moths (Drummond, 1984; Sánchez,

310 Hernández-Baños \& Cordero, 2011; Konagaya, Idogawa \& Watanabe, 2020) lacks a muscular

311 sheath. In this case, it will be particularly interesting the comparison of the monandrous pupal-

312 mating Heliconius with the polyandrous species of the same genus (Walters et al., 2012; Jiggins, 313 2017).

There are two general hypotheses to explain the evolutionary origin and maintenance of monandry in insects (Arnqvist \& Nilsson, 2000; Arnqvist \& Andrés, 2006; Hosken et al., 2009): either monandry is selected for in females when they maximize their fitness with just one mating, or sperm competition favours male adaptations that impose monandry on females that, otherwise, could obtain benefits from multiple mating. We suggest that the absence of a key adaptation required for the mechanical digestion of spermatophores sheds light on the selective pressures that favoured monandry in L. aripa. The muscular sheath of the CB is generally associated to the presence of signa (Sugawara, 1979; Drummond, 1984; Rogers \& Wells, 1984; Lai-Fook, 1986;

Kristensen, 2003; Lincango, Fernández \& Baixeras, 2013; Al-Wathiqui, Lewis \& Dopman, 2014; Meslin et al., 2015) and signa appear to be a general feature of Lepidoptera (Sánchez, Hernández-Baños \& Cordero, 2011). Thus, although a proper phylogenetic study is required, we hypothesize that the muscular sheath was lost in L. aripa and that this loss is a female adaptation to monandry. the importance of spermatophore-derived nutrients for female reproduction and favoured 
330

331

332

333

334

335

336

337

338

339

340

341

342

343

344

345

346

347

348

349

350

351

352

monandrous mating in females, possibly because in this way females reduce copulation time costs and predation risk during courtship and copulation. A recent study proposed this idea and presented evidence that anthropogenic nutritional enrichment of food plants has an effect on female mating frequency (Espeset et al., 2019). A comparison of an "agricultural population" (AP) of the butterfly Pieris rapae, where fertilizers, irrigation and low levels of pesticides resulted in increased availability of nitrogen in food plants (canola), with a non-agricultural population (NAP) showed that, as predicted, most females of the AP mated once whereas more than half of the females of the NAP mated two or three times (Espeset et al., 2019). In the case of L. aripa in our study site, the females lay eggs mostly in a non-cultivated plant (T. majus) that grows forming large patches in disturbed places like the side of roads, but also grows within the gardens of the University, where it at least receives irrigation. On the other hand, in other parts of the city, this butterfly uses as host plants cultivated vegetables that can be fertilized and are irrigated (such as cabbage, broccoli and cauliflower; CATIE/MIP, 1990). A second hypothesis is that monandry evolved in response to male adaptation to sperm competition. For example, if males evolved spermatophores that are difficult to digest to delay female remating, a point could be reached in which spermatophore digestion becomes excessively expensive due to physiological or ecological reasons, and favours females that avoid these costs by abandoning polyandry.

\section{Acknowledgements}

The research reported in this paper is part of the doctoral thesis of David Xochipiltecatl García (DXG) in the Posgrado en Ciencias Biológicas, Universidad Nacional Autónoma de México (UNAM). We thank Dr. Juan Núñez Farfán and Dr. Jorge Contreras for valuable criticism and 
353 suggestions on the project, and Raúl Iván Martínez for technical support. We thank the students

354 of Carlos Cordero's lab for discussion and support. We thank Dr. Boyan Zlatkov, Dr. Andrew

355 Stoehr and an anonymous reviewer for insightful commentaries that helped us to improve our

356 manuscript.

357

358

\section{REFERENCES}

359 Al-Wathiqui N, Lewis S, Dopman EB. 2014. Using RNA sequencing to characterize female reproductive genes between $\mathrm{Z}$ and $\mathrm{E}$ Strains of European Corn Borer moth (Ostrinia nubilalis). BMC Genomics 15:189 DOI 10.1186/1471-2164-15-189.

Al-Wathiqui N, Dopman EB, Lewis S. 2016. Postmating transcriptional changes in the female reproductive tract of the European corn borer moth. Insect Molecular Biology 25:629-645 DOI 10.1111/imb.12249.

Arnqvist G, Nilsson T. 2000. The evolution of polyandry: multiple mating and female fitness is insects. Animal Behaviour 60:145-164 DOI 10.1006/anbe.2000.1446.

Arnqvist G, Andrés JA. 2006. The effects of experimentally induced polyandry on female reproduction in a monandrous mating system. Ethology 112:748-756 DOI 10.1111/j.14390310.2006.01211.x.

Bissoondath CJ, Wiklund C. 1995. Protein content of spermatophores in relation to

371 monandry/polyandry in butterflies. Behavioral Ecology and Sociobiology 37:365-371 DOI 10.1007/BF00170583.

Bissoondath CJ, Wiklund C. 1996a. Effect of male mating history and body size on ejaculate 374 size and quality in two polyandrous butterflies, Pieris napi and Pieris rapae (Lepidoptera: 
375 Pieridae). Functional Ecology 10:457-464 DOI 10.2307/2389938.

376 Bissoondath CJ, Wiklund C. 1996b. Male butterfly investment in successive ejaculates in 377 relation to mating system. Behavioral Ecology and Sociobiology 39:285-292 DOI $37810.1007 / \mathrm{s} 002650050291$.

379 Boggs CL. 1990. A general model of the role of male-donated nutrients in female insects' 380 reproduction. The American Naturalist 136:598-617 DOI 10.1086/285118.

381 Boggs CL, Gilbert LE. 1979. Male contribution to egg production in butterflies: evidence for 382 transfer nutrients at mating. Science 206:83-84 DOI 10.1126/science.206.4414.83.

383 Brent CS, Byers JA, Levi-Zada A. 2017. An insect anti antiaphrodisiac. eLife 6:e24063 DOI 384 10.7554/eLife.24063.001.

385 Caballero-Mendieta N, Cordero C. 2013. Male mating costs in a butterfly that produces small 386 ejaculates. Physiological Entomology 38:318-325 DOI 10.1111/phen.12037.

387 Cannon RJC. 2020. Courtship and mating in butterflies. Wallingford UK: CABI.

388 Cardoso MZ, Roper JJ, Gilbert LE. 2009. Prenuptial agreements: Mating frequency predicts 389 gift-giving in Heliconius species. Entomologia Experimentalis et Applicata 131:109-114 DOI 390 10.1111/j.1570-7458.2009.00837.x.

391 CATIE/MIP. 1990. Guía para el manejo integrado de plagas del cultivo de repollo. Costa Rica: 392 CATIE.

393 Cordero C. 2000. Trade-off between fitness components in males of the polygynous butterfly 394 Callophrys xami (Lycaenidae): the effect of multiple mating on longevity. Behavioral Ecology 395 and Sociobiology 48:458-462 DOI 10.1007/s002650000261 
396

397

398

399

400

401

402

403

404

405

406

407

408

409

410

411

412

413

414

415

416

417

Cordero C. 2005. The evolutionary origin of signa in female Lepidoptera: natural and sexual selection hypotheses. Journal of Theoretical Biology 232:443-449 DOI 10.1016/j.jtbi.2004.08.031.

Cordero C, Baixeras J. 2015. Sexual Selection within the Female Genitalia in Lepidoptera. In:

Peretti VA, Aisenberg A, eds. Cryptic Female Choice in Arthropods: Patterns, Mechanisms and Prospects. Switzerland: Springer International Publishing, 325-350.

Díaz Batres ME, Llorente Bousquets J. 2011. Mariposas de Chapultepec. México:

Cospapalotl.

Drummond III BA. 1984. Multiple mating and sperm competition in the Lepidoptera. In: Smith RL, ed. Sperm Competition and the Evolution of Animal Mating Systems. New York: Academic Press, 291-370.

Dussourd DE, Harvis C, Meinwald J, Eisner T. 1989. Paternal allocation of sequestered plant pyrrolizidine alkaloid to eggs in the danaine butterfly Danaus gillipus. Experientia 45:896-898 DOI 10.1007/BF01954068.

Dussourd DE, Ubik K, Harvis C, Resch J, Meinwald J, Eisner T. 1988. Biparental defensive endowment of eggs with acquired plant alkaloid in the moth Utetheisa ornatrix. PNAS 85:59925996 DOI 10.1073/pnas.85.16.5992.

Eberhard WG. 1985. Sexual selection and animal genitalia. Harvard: Harvard University Press.

Eisner T, Meinwald J. 1995. The chemistry of sexual selection. PNAS 92:50-55 DOI 10.1073/pnas.92.1.50.

Espeset A, Kobiela ME, Sikkink KL, Pan T, Roy C, Snell-Rood EC. 2019. Anthropogenic increases in nutrients alter sexual selection dynamics: a case study in butterflies. Behavioral Ecology 30:598-608 DOI 10.1093/beheco/arz004. 
418 Ferkau C, Fischer K. 2006. Cost of reproduction in male Bicyclus aninana and Pieris napi

419 butterflies: effects of mating history and food limitations. Ethology 112:1117-1127 DOI

$420 \quad 10.111 / \mathrm{j} .1439-0310.2006 .01266 . x$

421 Galicia I, Sánchez V, Cordero C. 2008. On the function of signa, a genital trait of female

422 Lepidoptera. Annals of the Entomological Society of America 101:786-793 DOI 10.1603/0013423 8746(2008)101[786:OTFOSA]2.0.CO;2.

424 González A, Rossini C, Eisner M, Eisner T. 1999. Sexually transmitted chemical defense in a 425 moth (Utetheisa ornatrix). PNAS 96:5570-5574 DOI 10.1073/pnas.96.10.5570.

426 Hinton HE. 1964. Sperm transfer in insects and the evolution of haemocelic insemination. In:

427 Highnam KC, ed. Insect Reproduction. London: Symposium of the Royal Entomological Society 428 of London, 95-107.

429 Hosken DJ, Stockley P, Tregenza T, Wedell N. 2009. Monogamy and the battle of the sexes. 430 Annual Review of Entomology 54:36-378 DOI 10.1146/annurev.ento.54.110807.090608.

431 Jiggins CD. 2017. The ecology and evolution of Heliconius butterflies. Oxford UK: Oxford 432 University Press.

433 Kaitala A, Wiklund C. 1995. Female mate choice and mating costs in the polyandrous butterfly 434 Pieris napi (Lepidoptera: Pieridae). Journal of Insect Behavior 8:355-363 DOI $43510.1007 / \mathrm{BF} 01989364$.

436 Karlsson B. 1998. Nuptial gifts, resource budgets, and reproductive output in a polyandrous 437 butterfly. Ecology 79:2931-2940 DOI 10.1890/0012-9658(1998)079[2931:NGRBAR]2.0.CO;2.

438 Konagaya T, Idogawa N, Watanabe M. 2020. Destination of apyrene sperm following 439 migration from the bursa copulatrix in the monandrous swallowtail butterfly Byasa alcinous. 
441 Kristensen NP. 2003. Reproductive organs. In: Kristensen NP, ed. Handbook of Zoology 4:

442 Arthropoda: Insecta, Part 36, Lepidoptera, Moths and Butterflies, 2: Morphology, Physiology,

443 and Development. Berlin: De Gruyter, 427-447.

444 Lai-Fook J. 1986. The virgin bursa copulatrix of the butterfly, Calpodes. Tissue \& Cell 18:545445558 DOI 10.1016/0040-8166(86)90020-0.

446 Lai-Fook J. 1991. Absorption of phosphorus from the spermatophore through the cuticle of the 447 bursa copulatrix of the butterfly, Calpodes ethlius. Tissue \& Cell 23:247-259 DOI $448 \quad 10.1016 / 0040-8166(91) 90079-9$.

Labine PA. 1964. The population biology of the butterfly Euphydryas editha. I. Barriers to 450 multiple insemination. Evolution 18:335-336 DOI 10.1111/j.1558-5646.1964.tb01607.x.

Lincango P, Fernández G, Baixeras J. 2013. Microstructure and diversity of the bursa copulatrix wall in Tortricidae (Lepidoptera). Arthropod Structure and Development 42:247-256 DOI 10.1016/j.asd.2013.01.003.

Marshall LD. 1985. Protein and lipid composition of C. philodice and C. eurytheme

455 spermatophores and their changes over time (Pieridae). Journal of Research on the 456 Lepididoptera 24:21-30. organ in the female reproductive tract borrows genes from multiple organ systems to adopt critical functions. Molecular Biology and Evolution 32:1567-1580 DOI 10.1093/molbev/msv048. 
461 Meslin C, Cherwin TS, Plakke MS, Hill J, Small BS, Goetz BJ, Wheat CW, Morehouse NI,

462 Clark NL. 2017. Structural complexity and molecular heterogeneity of a butterfly ejaculate 463 reflect a complex history of selection. Proceedings of the National Academy of Sciences USA

464 114:E5406-E5413 DOI doi/10.1073/pnas.1707680114

465

466

467

468

469

470

471

472

Molleman F, van Grusven RHA, Liefting M, Zwaan B, Brakefield PM. 2005. Is male puddling behavior of tropical butterflies targeted at sodium for nuptial gifts or activity? Biological Journal of the Linnean Society 86:345-361 DOI 10.1111/j.1095-8312.2005.00539.x.

Oberhauser KS. 1989. Effects of spermatophore on male and female monarch butterfly reproductive success. Behavioral Ecology and Sociobiology 25:237-246 DOI 10.1007/BF00300049.

Oberhauser KS. 1992. Rate of ejaculate breakdown and intermating intervals in monarch butterflies. Behavioral Ecology and Sociobiology 31:367-373 DOI 10.1007/BF00177777.

Pivnick KA, McNeil JN. 1987. Puddling in butterflies: sodium affects reproductive success in Thymelicus lineola. Physiological Entomology 12:461-472 DOI 10.1111/j.13653032.1987.tb00773.x.

Pizzari T, Wedell N. 2013. The polyandry revolution. Philosophical Transactions of the Royal Society B 368, 20120041 DOI 10.1098/rstb.2012.0041.

Plakke MS, Deutsch AB, Meslin C, Clark NL, Morehouse NI. 2015. Dynamic digestive physiology of a female reproductive organ in a polyandrous butterfly. Journal of Experimental Biology 218:1548-1555 DOI 10.1242/jeb.118323.

Plakke MS, Walker JL, Lombardo JB, Goetz BJ, Pacella GN, Durrant JD, Clark NL, Morehouse NI. 2019. Characterization of female reproductive proteases in a butterfly from 
483 functional and evolutionary perspectives. Physiological and Biochemical Zoology 92:579-590

484 DOI 10.1086/705722.

485 Rogers SH, Wells H. 1984. The structure and function of the bursa copulatrix of the monarch

486 butterßy (Danaus plexippus). Journal of Morphology 180:213-221 DOI

$487 \quad 10.1002 /$ jmor.1051800305.

488 Sanchez VM, Hernandez-Baños BE, Cordero C. 2011. The evolution of a female genital trait 489 widely distributed in the Lepidoptera: comparative evidence for an effect of sexual coevolution. $490 \quad$ PLoS ONE 6:e22642 DOI 10.1371/journal.pone.0022642.

491 Sánchez VM, Cordero C. 2014. Sexual coevolution of spermatophore envelopes and female 492 genital traits in butterflies: Evidence of male coercion? PeerJ 2:e247 DOI 10.7717/peerj.247.

493 Shapiro AM. 1982. Survival of refrigerated Tatochila butterflies (Lepidoptera: Pieridae) as an 494 indicator of male nutrient investment in reproduction. Oecologia 53:139:140 DOI

495 10.1007/BF00377149

496 Simmons LW. 2001. Sperm competition and its evolutionary consequences in the insects.

497 Princeton: Princeton University Press.

498 Smedley SR, Eisner T. 1996. Sodium: a male's moth gift to its offsping. PNAS 93:809-813 DOI

$499 \quad 10.1073 /$ pnas.93.2.809.

500 Sugawara T. 1979. Stretch reception in the bursa copulatrix of the butterfly, Pieris rapae

501 crucivora, and its role in behaviour. Journal of Comparative Physiology A 130:191-199 DOI

$50210.1007 / \mathrm{BF} 00614605$.

503 Taylor ML, Price TAR, Wedell N. 2014. Polyandry in nature: a global analysis. Trends in

504 Ecology and Evolution 29:376-383 DOI 10.1016/j.tree.2014.04.005. 
505 Torres-Vila LM, Jennions MD. 2005. Male mating history and female fecundity in

506 Lepidoptera: do male virgins make better partners? Behavioral Ecology and Sociobiology

507 57:318-326 DOI 10.1007/s00265-004-0857-7.

508 Torres-Vila LM, Rodríguez-Molina MC, Jennions MD. 2004. Polyandry and fecundity in the

509 Lepidoptera: can methodological and conceptual approaches bias outcomes? Behavioral Ecology

510 and Sociobiology 55:315-324 DOI 10.1007/s00265-003-0712-2.

511 Tschudi-Rein K, Benz G. 1990. Mechanisms of sperm transfer in female Pieris brassicae.

512 Annals of the Entomological Society of America 83:1158-1164 DOI 10.1093/aesa/83.6.1158.

513 Vahed K. 1998. The function of nuptial feeding in insects: a review of empirical studies.

514 Biological Reviews 73:43-78 DOI 10.1111/j.1469-185X.1997.tb00025.x.

515 Walters JR, Stafford C, Hardcastle TJ, Jiggins CD. 2012. Evaluating female remating rates in

516 light of spermatophore degradation in Heliconius butterflies: pupal-mating monandry versus

517 adult-mating polyandry. Ecological Entomology 37:257-268 DOI 10.1111/j.1365-

$518 \quad 2311.2012 .01360 . x$.

519 Watanabe M. 2016. Sperm competition in butterflies. Japan: Springer.

520 Watanabe M, Sato KA. 1993. A spermatophore structured in the bursa copulatrix of the small 521 white Pieris rapae (Lepidoptera, Pieridae) during copulation and its sugar content. Journal of 522 Research on the Lepidoptera 32:26-36.

523 Wedell N. 2005. Female receptivity in butterflies and moths. Journal of Experimental Biology 524 208:3433-3440 DOI 10.1242/jeb.01774. 
Figure 1

Figure1 Female genitalia of the butterfly Leptophobia aripa.

(A) Genitalia of a virgin female: note the empty corpus bursae (cb) and the signum (si) near the junction (cervix) with the ductus bursae (db). (B) Corpus bursae and ductus bursae of a mated female: note the spermatophore almost filling the corpus bursae and the collum of the spermatophore filling the ductus bursae. Scale bars $A=500 \mu \mathrm{m} ; \mathrm{B}=1000 \mu \mathrm{m}$. 


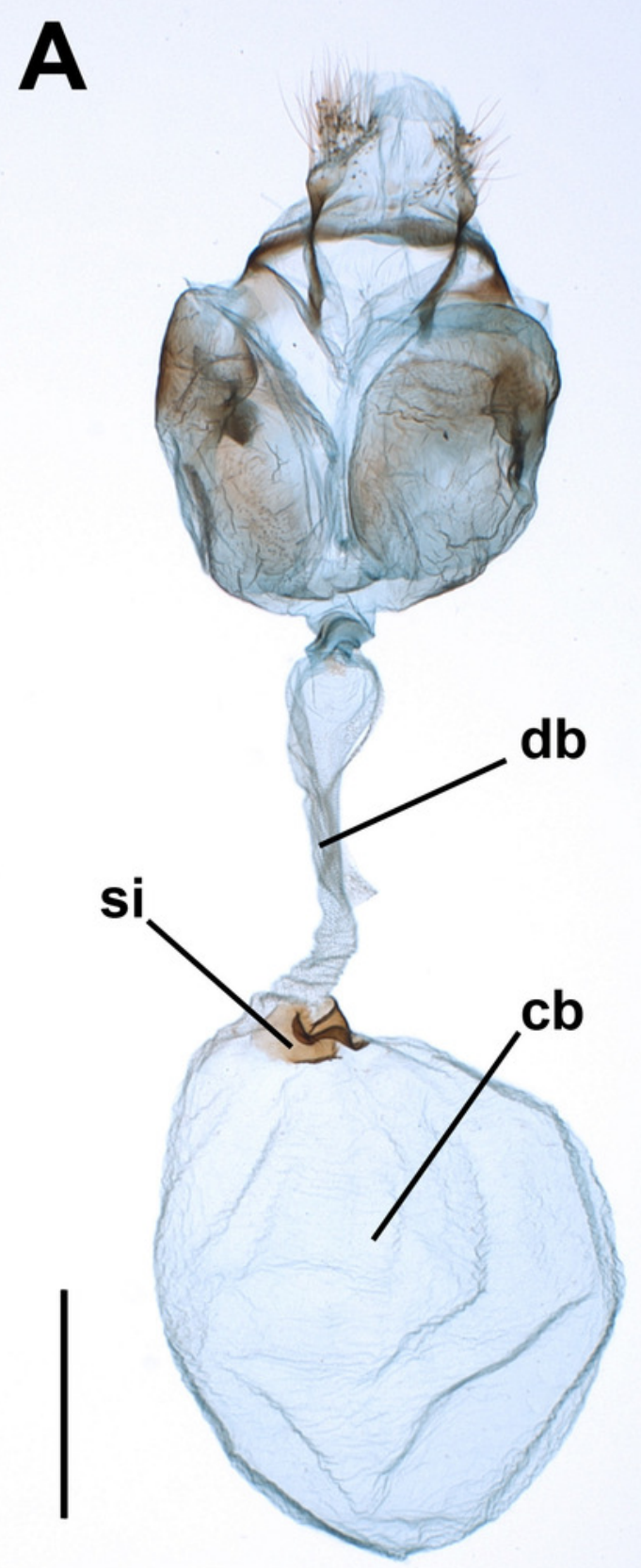

\section{B}

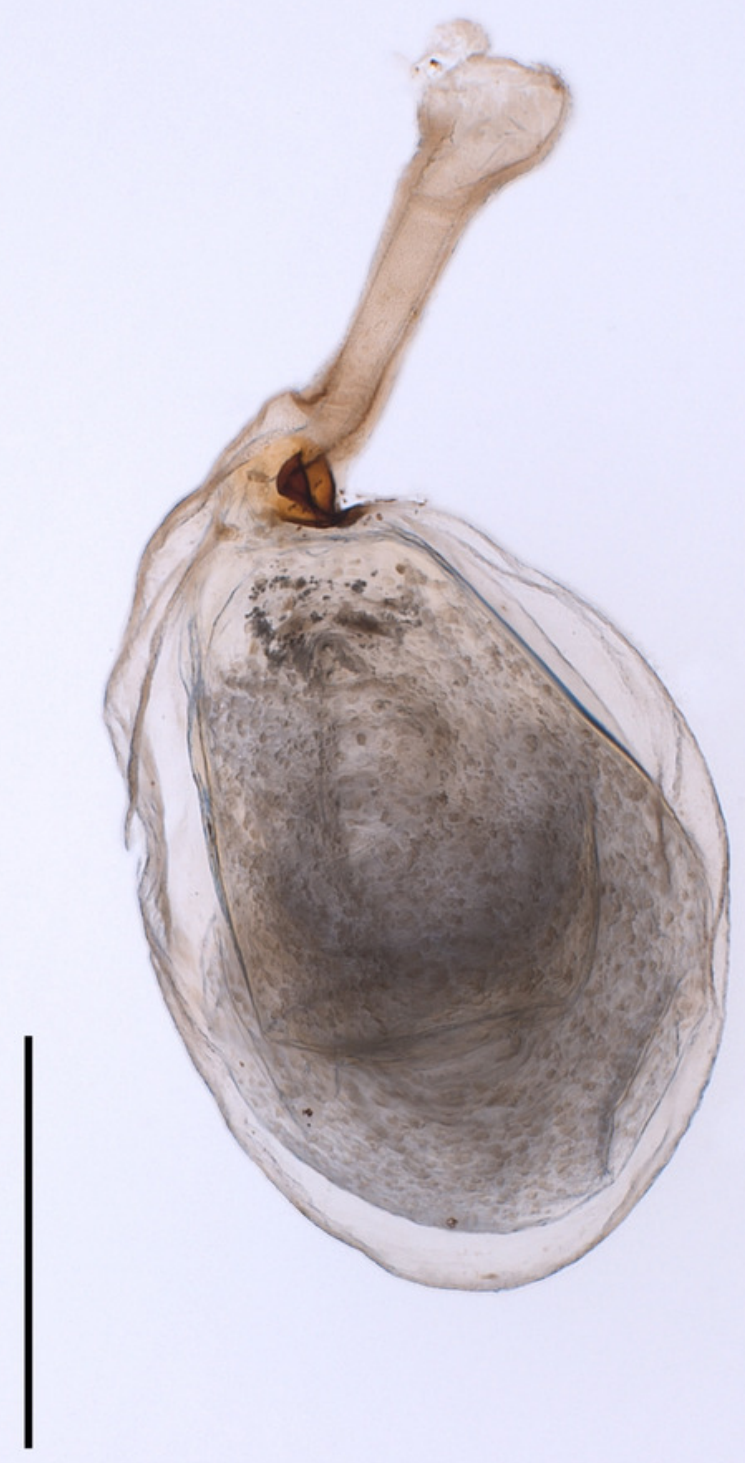


Figure 2

Figure 2 The spermatophores are not digested within the corpus bursae of female Leptophobia aripa butterflies.

Typical examples of spermatophores showing that they remain intact in the $C B$ independently of the time elapsed after the end of copulation (number of hours written besides each photograph) and of the fact that females laid eggs. Scale bar $=1 \mathrm{~mm}$. 


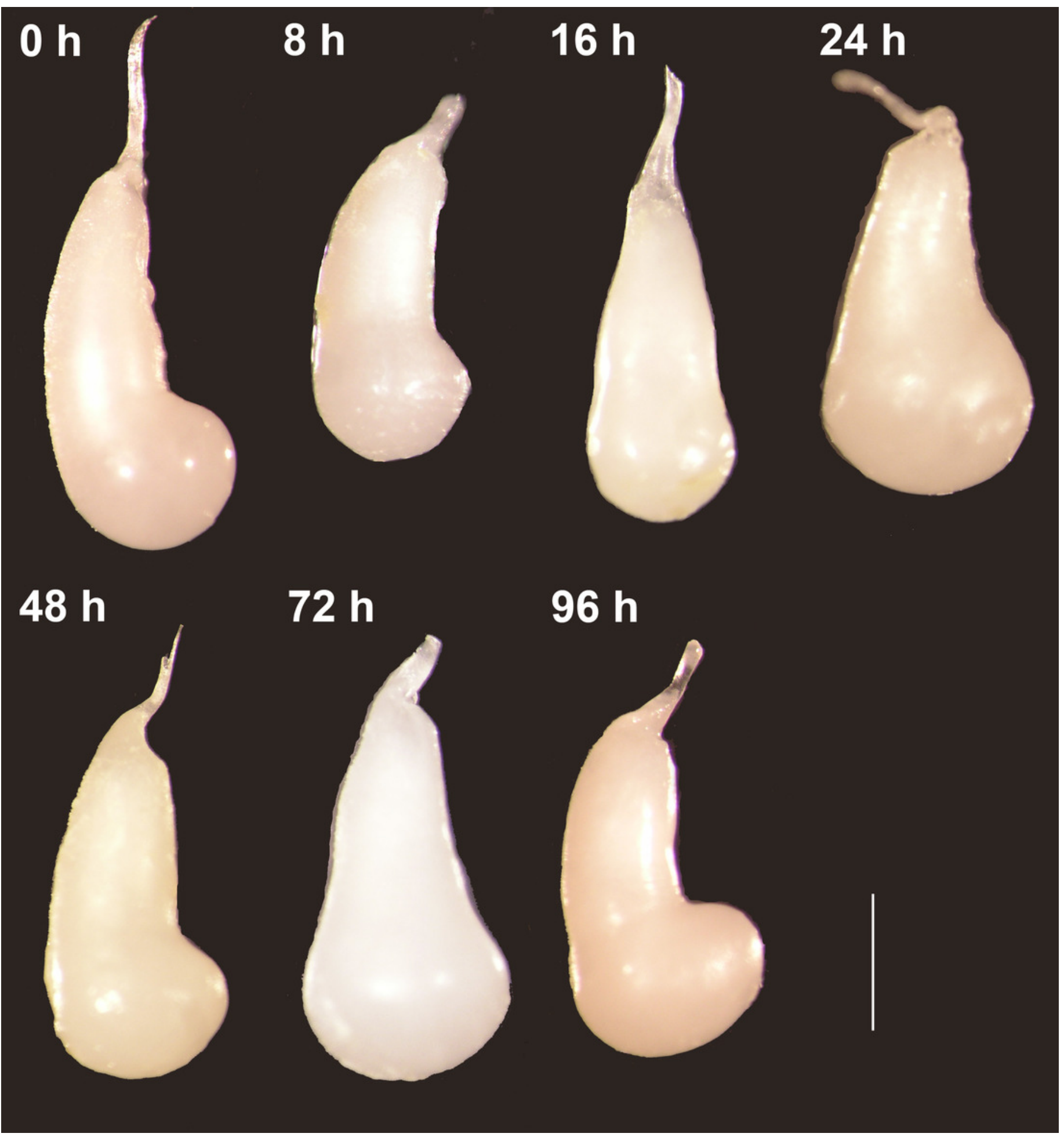




\section{Figure 3}

Area covered by the spermatophore (a proxy of its size) as a function of time elapsed after the end of copulation.

For each time, the Median (black line), $25 \%$ and $75 \%$ quartiles (grey box) and minimum and maximum values (whiskers) are shown (an outlier was detected at $24 \mathrm{~h}$ ). Time after copulation had no effect on spermatophore area (Kruskal-Wallis test: $H=4.26, P=0.64, d f=$ $6)$.

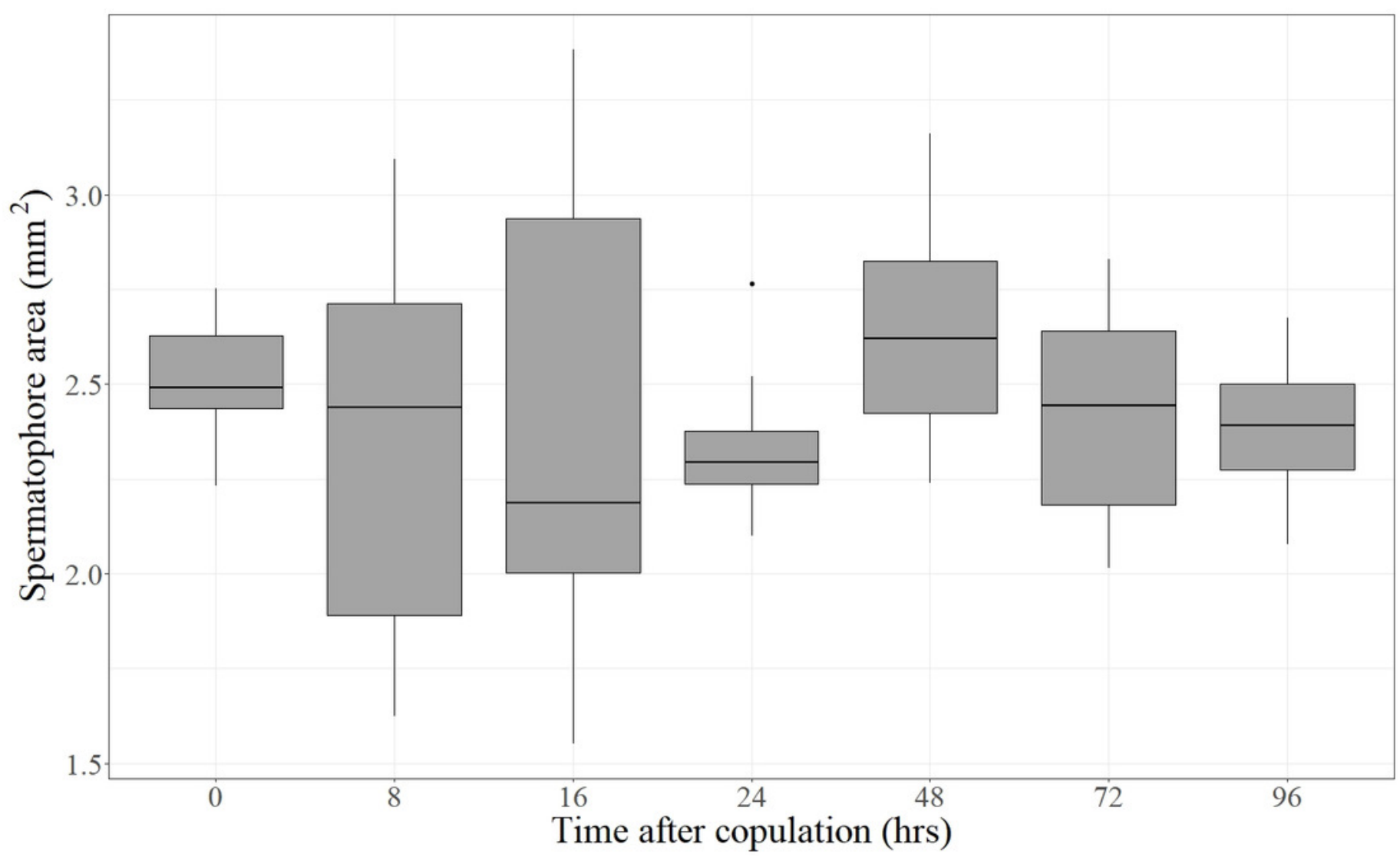




\section{Figure 4}

SEM images of the spermatophore, bursa copulatrix and its associated muscles, of the butterfly Leptophobia aripa and the spruce cotton leafworm Spodoptera littoralis.

(A) An intact spermatophore obtained from a female of $L$. aripa collected while laying eggs, taken to the laboratory and allowed to continue laying eggs for two more days; notice the tubular collum. (B) $C B$ and $D B$ of $L$. aripa showing the muscular lining of the $D B$; the $C B$ appears corrugated, with no muscle vestiture. (C) CB and DB of the African cotton leafworm showing a complex muscular lining; detail of the muscular area in the white rectangle is shown in F. (D) Inner surface of the CB of $L$. aripa showing a complete absence of pores. (E) Close-up of the "junction" area of the $C B$ and the $D B$ (the cervix) in L. aripa showing muscle fibers covering the $D B$, absent on the $C B$. (F) Detail of the muscle lining of the $C B$ of $S$. littoralis marked by the white rectangle in $\mathrm{C}$. Abbreviation: $\mathrm{co}$, collum. Scale bars $\mathrm{A}$ and $\mathrm{B}=$ $500 \mu \mathrm{m}, \mathrm{C}=1000 \mu \mathrm{m}, \mathrm{D}=5 \mu \mathrm{m}, \mathrm{E}=150 \mu \mathrm{m}, \mathrm{F}=100 \mu \mathrm{m}$. 

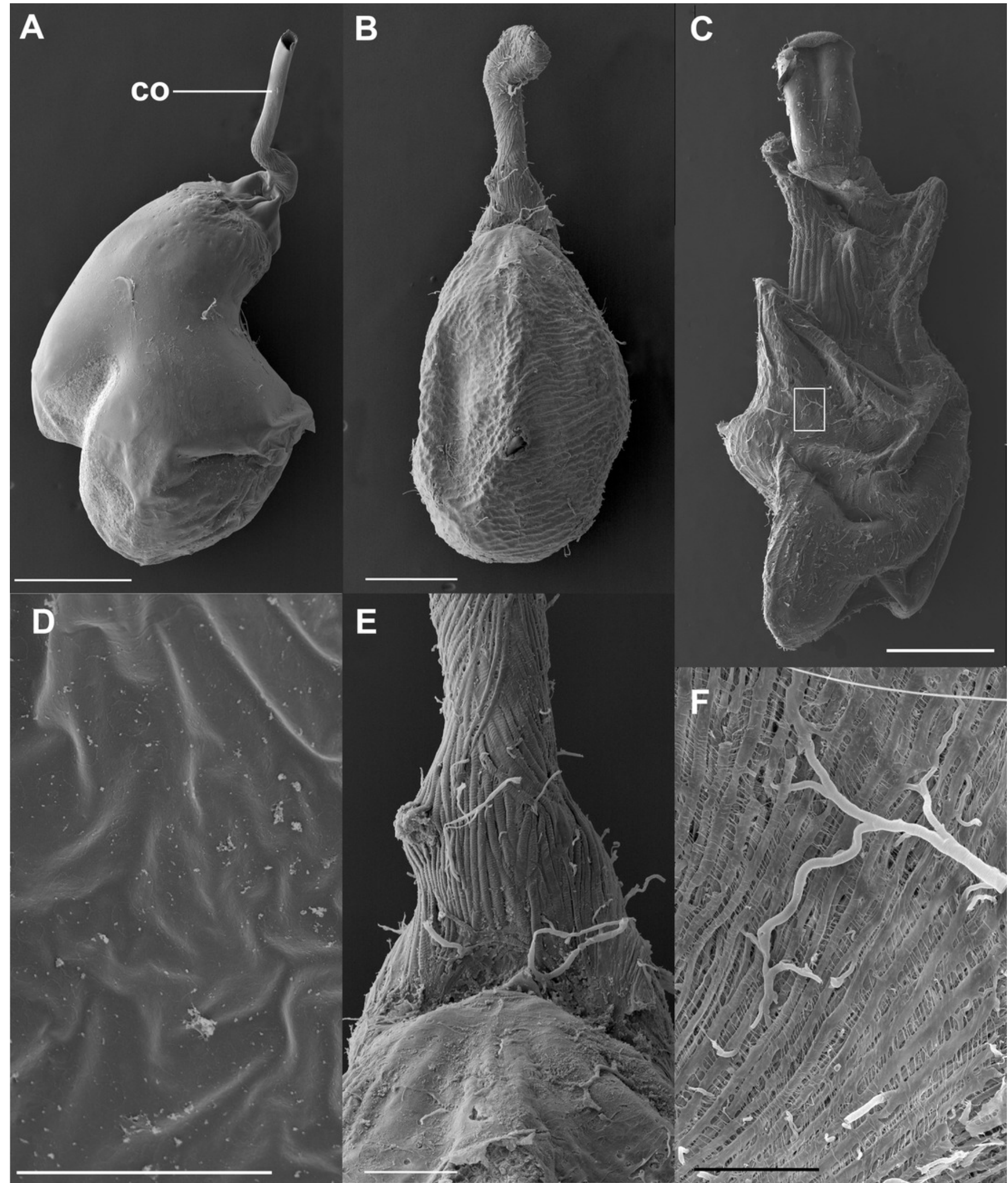